\title{
Study on Optimizing High-Gradient Magnetic Separation-Part 2: Experimental Evaluation of the Performance of a New Designed Magnetic Filter
}

\author{
Yonas S. Shaikh, Christian Seibert, Percy Kampeis \\ Trier University of Applied Sciences, Environmental Campus Birkenfeld, Institute for Biotechnical Process \\ Design, Birkenfeld, Germany \\ Email:y.shaikh@umwelt-campus.de
}

Received 24 March 2016; accepted 28 May 2016; published 31 May 2016

Copyright (C) 2016 by authors and Scientific Research Publishing Inc.

This work is licensed under the Creative Commons Attribution International License (CC BY). http://creativecommons.org/licenses/by/4.0/

(c) (i) Open Access

\begin{abstract}
The introduction of functionalized magnetizable particles and high-gradient magnetic separation represents a time and money saving alternative to conventional purification and separation unit operations in the biotechnical sector. This technique has some advantages especially for the recycling of immobilized enzymes. A new magnetic filter with sight glasses was constructed and produced to study the performance of high-gradient magnetic separation at varied parameters. By optical analysis the buildup of a clogging was identified as the major parameter which affected the separation performance. For the cleaning procedure, a two-phase flow of water with highly dispersed air bubbles was tested which led to a nearly complete cleaning of the filter chamber.
\end{abstract}

\section{Keywords}

Magnetic Particles, Magnetic Filtration, High-Gradient Magnetic Separation, Enzyme, Biocatalysis

\section{Introduction}

High-gradient magnetic separation is a technique used for several separation tasks. The use of the magnetic force also enables a simple separation of a biotechnological catalyst which is immobilized on a magnetizable carrier. Furthermore by using nano-or micron-sized spherical particles, the mass specific outer surface area gets very large. Because there is no need of additionally inner surface area, the biocatalytic active surface is easily accessible due to the absence of porous diffusion. This provides major advantages for the reaction due to better 
mass transfer in comparison to porous carriers [1] [2]. In a high-gradient magnetic separator, a filter matrix is inserted in the filter chamber to build a highly inhomogeneous magnetic field [3]-[8]. During the research on optimizing and improving high-gradient magnetic separation, it was found that the magnetic particle deposits on the filter matrix influenced the particle retention. In the publications of Menzel et al. [9] and Mizuno et al. [10] particle deposits were shown after a filtration by taking the filter matrix out of the filter chamber. Furthermore the matrices used in previous studies were made primarily of stacked wire meshes with varied wire diameters and amounts of meshes. Hereby the retention characteristics and separation performances were studied in detail without characterizing the location and impact of the particle deposits [11]-[20]. In the work of Käppler [21], a model for estimating the particle load in dependence to the filter length was introduced under the assumption that the magnetic particle deposits were distributed homogeneously over the cross-section perpendicular to the fluid flow.

In order to obtain information on the location of the deposits of magnetizable particles, a filter chamber with sight glasses made of quartz (patent pending with reference number DE102012023382.5) was constructed and tested with different matrices, particle suspensions and volume flows. The particle concentration in the filtrate was measured at-line in order to quantify the filter performance. This was supplemented by taking photos of the deposits of the magnetizable particles during filtration.

After the separation of the magnetizable carrier with the immobilized enzymes, the filter chamber has to be rinsed to recycle the biocatalyst. In previous studies, the cleaning procedure of high-gradient magnetic separators for biotechnological applications was performed mainly by 1) pumping a wash buffer with high velocity through the filter chamber, 2) applying intermediary pressured air hits, 3) pumping sequentially water and air through the filter, 4) using ultrasonic oscillators or 5) using pneumatic vibrators [15] [22]. The best rinsing efficiencies were found with pneumatic vibrators and the sequenced inlet of water and air. The installation of a pneumatic vibrator cannot be realized on magnetic filters, which include sensible parts as quartz glasses or measurement instruments. Therefore the two-phase rinsing procedure was tested and improved in efficiency.

\section{Material \& Methods}

The high-gradient magnetic separator type HGF10 from the company Steinert Elektromagnetbau GmbH is equipped with N42 permanent magnets, which can be rotated by an electrical motor. Hereby the magnetic field within the magnetic yoke can be switched on and off [14]. The magnetic pole surfaces of the yoke have an area of $24 \mathrm{~mm}$ by $80 \mathrm{~mm}$ each and a distance of $26 \mathrm{~mm}$. The average flux density is $0.35 \mathrm{~T}$. In Figure 1(A) a photo of the separator can be seen. In Figure 1(B) the optimized filter chamber is shown with sight glasses made of quartz placed within the magnetic yoke. The feed pump is a peristaltic pump of the type Ismatec ${ }^{\circledR}$ MCP from the company IDEX Health \& Science GmbH with a pump head type Easy-Load 2 from the company Masterflex ${ }^{\circledR}$ SE. The pump tubing type C-Flex also from the company Masterflex ${ }^{\circledR}$ SE has an inner diameter of $4.8 \mathrm{~mm}$. The other tubing lines of the plant are of polyurethane with an inner diameter of $6 \mathrm{~mm}$ and quick connectors made

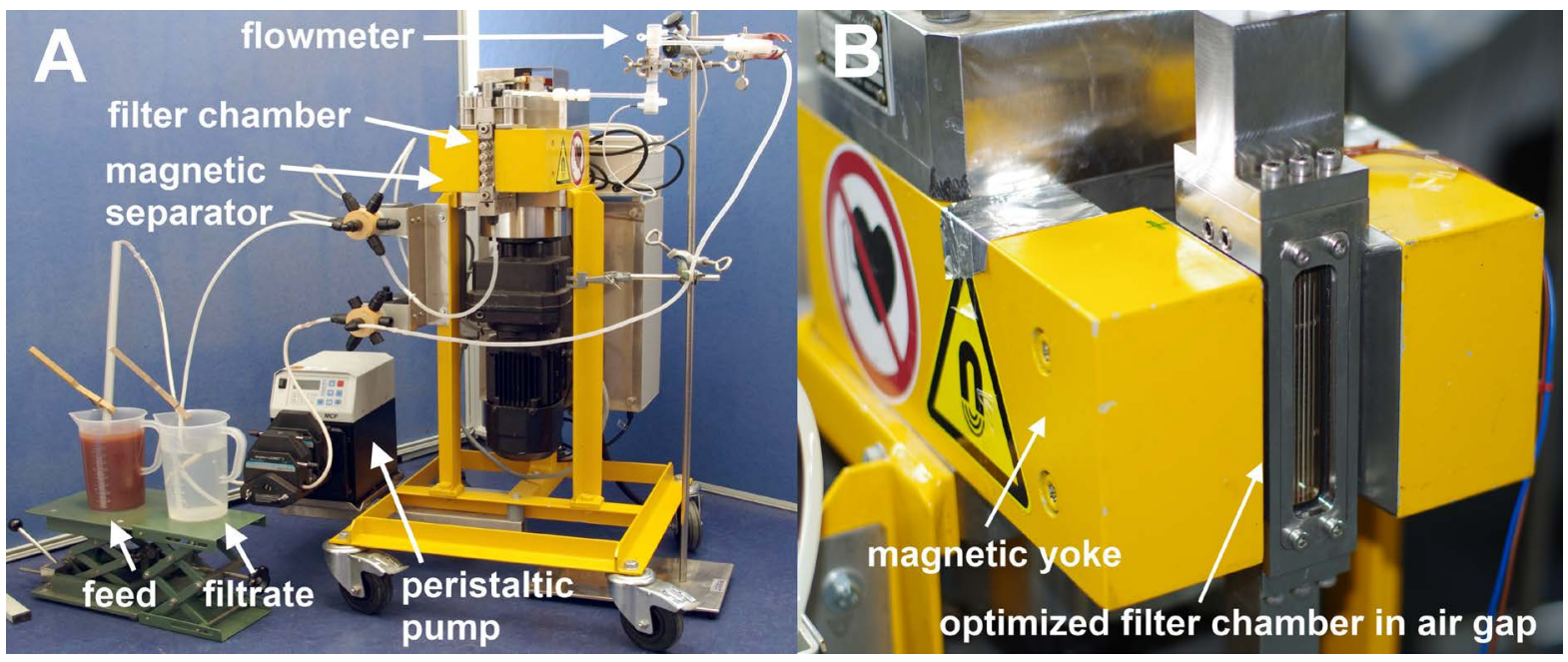

Figure 1. High-gradient magnetic separator type Steinert HGF10 (A) and the optimized filter chamber (B). 
of polyoxymethylene from the company Riegler \& Co. KG.

The filter housing is made of stainless steel (AISI 316Ti) and consists of an in- and an outlet device and the filter chamber. These parts were made by milling with a CNC machine (Deckel Maho DMU $60 \mathrm{~T}$ ). Subsequently the inner volume of the filter chamber was electro eroded. The quartz sight glasses (Suprasil 2 Grade A) were made to measure by the company Aachener Quarz-Glas Technologie Heinrich. The inner volume of the magnetic filter is $60 \mathrm{~mL}$ and the filter matrix is placed in the center of the chamber. For the homogenization of the fluid profile at the start of the filter matrix a 3D-printed flow homogenisator, which was made of plastic (VeroClear-RGD810), was installed in the experiments.

The magnetizable particles (M-PVA C22 magnetic beads) used in this study were produced by PerkinElmer chemagen Technology GmbH with a polydispersed diameter distribution ranging from $<1 \mu \mathrm{m}$ to $10 \mu \mathrm{m}$. The particles consisted of equal proportions of magnetite and polyvinyl alcohol and had a dry density of $2 \mathrm{~kg} \cdot \mathrm{dm}^{-3}$. At the outlet of the magnetic filter the particle concentration in the filtrate was measured with an UV/VIS spectrometer Ultrospec 2100 pro from the company GE Healthcare which was equipped with a flow-through cell. The measurement is explained in detail in Shaikh et al. [23]. For the quantification of the particle size distribution, samples were collected and measured with the particle analyzer Analysette 22 MicroTec from the company Fritsch GmbH. The device measures laser light diffraction caused by the particles and calculates the particle size distribution from the resulting pattern. The homogenization of magnetizable particle suspensions was performed with an ultrasonic homogenizer Sonopuls HD 2200 from the company Bandelin electronic GmbH \& Co. KG with a flow-through cell. During filtrations the volume flow was measured with an ultrasonic flow meter Leviflow LFS-008 from the company Levitronix GmbH and controlled via a PID controller [24].

\section{Results}

\subsection{Particle Handling}

The suspension of magnetizable particles in the feed vessel must be stirred with a minimum speed to ensure an adequately homogenized suspension. In order to measure the required stirrer speed a $1.5 \mathrm{~L}$ magnetizable particle suspension with a concentration of $0.2 \mathrm{~g} \cdot \mathrm{L}^{-1}$ M-PVA C22 was stirred with a 4-wing propeller stirrer $(\mathrm{d}=5 \mathrm{~cm}$, $\mathrm{d}_{\text {Stirrer }} / \mathrm{d}_{\text {Vessel }}=0.385$ ) in the center of the cylindrical volume of $3 \mathrm{~L}$. First the magnetizable particles were completely homogenized for 30 minutes at $720 \mathrm{rpm}$. At this time the particle concentration at the top of the fluid was measured and used as a reference for the following measurements. Then the stirrer was switched off and after magnetically assisted sedimentation the particle concentration was measured again. In the following the stirrer was started with different revolutions per minute (60, 180 and $360 \mathrm{rpm})$ without applying a magnet. After 10 minutes of stirring the concentration of the suspension was measured and the mixing efficiency $\mathbf{M}_{10 \mathrm{~min}}$ (see Equation (1)) was calculated with the measured concentrations c and compared.

$$
\mathrm{M}_{10 \min }=\frac{c(t=10 \mathrm{~min}, \mathrm{rpm})}{c(t=30 \mathrm{~min}, \mathrm{rpm}=720)}
$$

The measurements were carried out in triplet repetition and after each run the particles were magnetically sedimented and the concentration was checked to ensure the sedimentation. It was found that the mixing efficiency $\mathrm{M}_{10 \text { min }}$ was satisfactory above $180 \mathrm{rpm}$ (see Table 1).

Cleaning procedures of production plants are commonly carried out with concentrated acids to dissolve deposits of solid matter. On the other hand adsorption and elution of biomolecules on or from the functionalized magnetizable particles takes place at lowered $\mathrm{pH}$ values, as for example described in Meyer et al. [7], Hoffmann [22] or Holschuh and Schwämmle [25]. The behavior of the M-PVA C22 particles at low pH values was studied by incubating them in formic, acetic and hydrochloric acid for 30 minutes. The acids had $\mathrm{pH}$ values in a range

Table 1. Particle concentration in the suspension and mixing efficiency $\mathrm{M}_{10 \mathrm{~min}}$ at different stirrer speeds.

\begin{tabular}{|c|c|c|c|c|c|}
\hline & $\begin{array}{c}720 \mathrm{rpm} \\
(\mathrm{t}=30 \mathrm{~min})\end{array}$ & $\begin{array}{c}0 \mathrm{rpm} \\
\text { (sedimented) }\end{array}$ & $\begin{array}{c}60 \mathrm{rpm} \\
(\mathrm{t}=10 \mathrm{~min})\end{array}$ & $\begin{array}{c}180 \mathrm{rpm} \\
(\mathrm{t}=10 \mathrm{~min})\end{array}$ & $\begin{array}{c}360 \mathrm{rpm} \\
(\mathrm{t}=10 \mathrm{~min})\end{array}$ \\
\hline Concentration $\left[\mathrm{g} \cdot \mathrm{L}^{-1}\right]$ & $0.228 \pm 0.001$ & $0.002 \pm 0.001$ & $0.151 \pm 0.001$ & $0.235 \pm 0.002$ & $0.231 \pm 0.001$ \\
\hline $\mathrm{M}_{10 \text { min }}[-]$ & - & - & 0.65 & 1.00 & 1.00 \\
\hline
\end{tabular}


from 0.12 to 3.19. It was observed that the M-PVA C22 particles agglomerate under this circumstances. The median particle diameter $d_{50}$ was increased with decreasing $\mathrm{pH}$ value with a linear function (see Equation (2) with $\mathrm{R}^{2}=0.81$ )

$$
\mathrm{d}_{50}[\mu \mathrm{m}]=-0.52 \cdot \mathrm{pH}+8.34
$$

Furthermore the behavior of M-PVA C22 particles in phosphate buffered saline (PBS) with salt concentrations of 15 and $79 \mathrm{~g} \cdot \mathrm{L}^{-1}$ and $\mathrm{pH}$ values ranging from 4 to 7 was studied. The particles were incubated for 24 hours in the solution and then the particle diameter distribution was measured. The salt solution was prepared by mixing sodium chloride and sodium dihydrogen phosphate in a 1:1 proportion into water. The $\mathrm{pH}$ value was adjusted afterwards by adding sodium hydroxide.

In Figure 2 a plot of the median particle diameter $d_{50}$ in relation to the salt concentration and $\mathrm{pH}$ value is shown. According to the measured data the addition of high amounts of salts to the suspension could prevent the agglomeration of the M-PVA C22 particles even at low $\mathrm{pH}$ values.

The dispersion of magnetizable particles was studied in an ultrasonic homogenizer in flow-through mode with a volume flow of $50 \mathrm{~mL} \cdot \mathrm{min}^{-1}$. Three magnetic particle suspensions S1-S3 (1, 5 and $10 \mathrm{~g} \cdot \mathrm{L}^{-1} \mathrm{M}-\mathrm{PVA}$ C22) were pumped through the homogenizer consecutively five times. After each cycle the particle size distribution was measured with the same sample particle concentration (approximately $0.1 \mathrm{~g} \cdot \mathrm{L}^{-1}$ ). The power of the homogenizer was adjusted to $x=25,50$ and $100 \%$ of $200 \mathrm{~W}$. It can be assumed that the power input of the ultrasonic homogenization was not affected by the particle concentration. Figure 3 shows the measured $d_{50}$ values after each homogenization cycle. When the power was adjusted to $50 \%$ or $100 \%$ the particle concentration of the suspension did not affect the median particle diameter. But when the power was adjusted to $25 \%$, the median particle diameter of the low concentrated suspension with $1 \mathrm{~g} \cdot \mathrm{L}^{-1}$ was greater than with $5 \mathrm{or} 10 \mathrm{~g} \cdot \mathrm{L}^{-1}$. It seemed to be that the amount of disaggregated particles was larger when a dense suspension is homogenized than in case of a light suspension. This means that the median particle diameter is affected by the amount of particles flowing through the ultrasonic field. This effect was obvious up to the fourth homogenization cycle when the power was adjusted to $25 \%$.

The particles could be dispersed from $d_{50}=5.4 \mu \mathrm{m}$ to either $d_{50}=3.8 \mu \mathrm{m}$ with $\mathrm{x}=25 \%$ or to $3.6 \mu \mathrm{m}$ with $\mathrm{x} \geq$ $50 \%$.

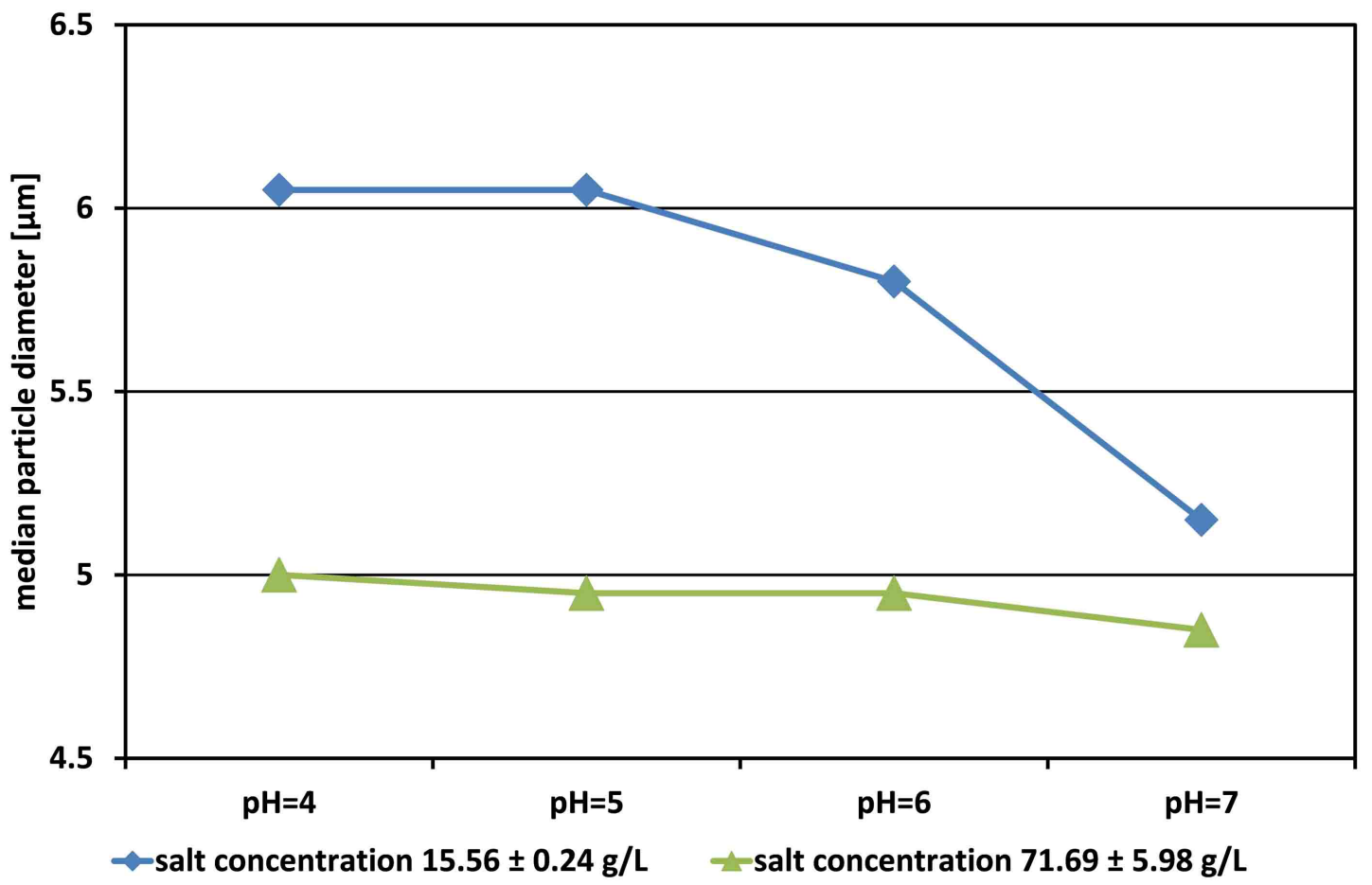

Figure 2. Measured median particle diameter in relation to salt concentration (PBS) and pH value. 


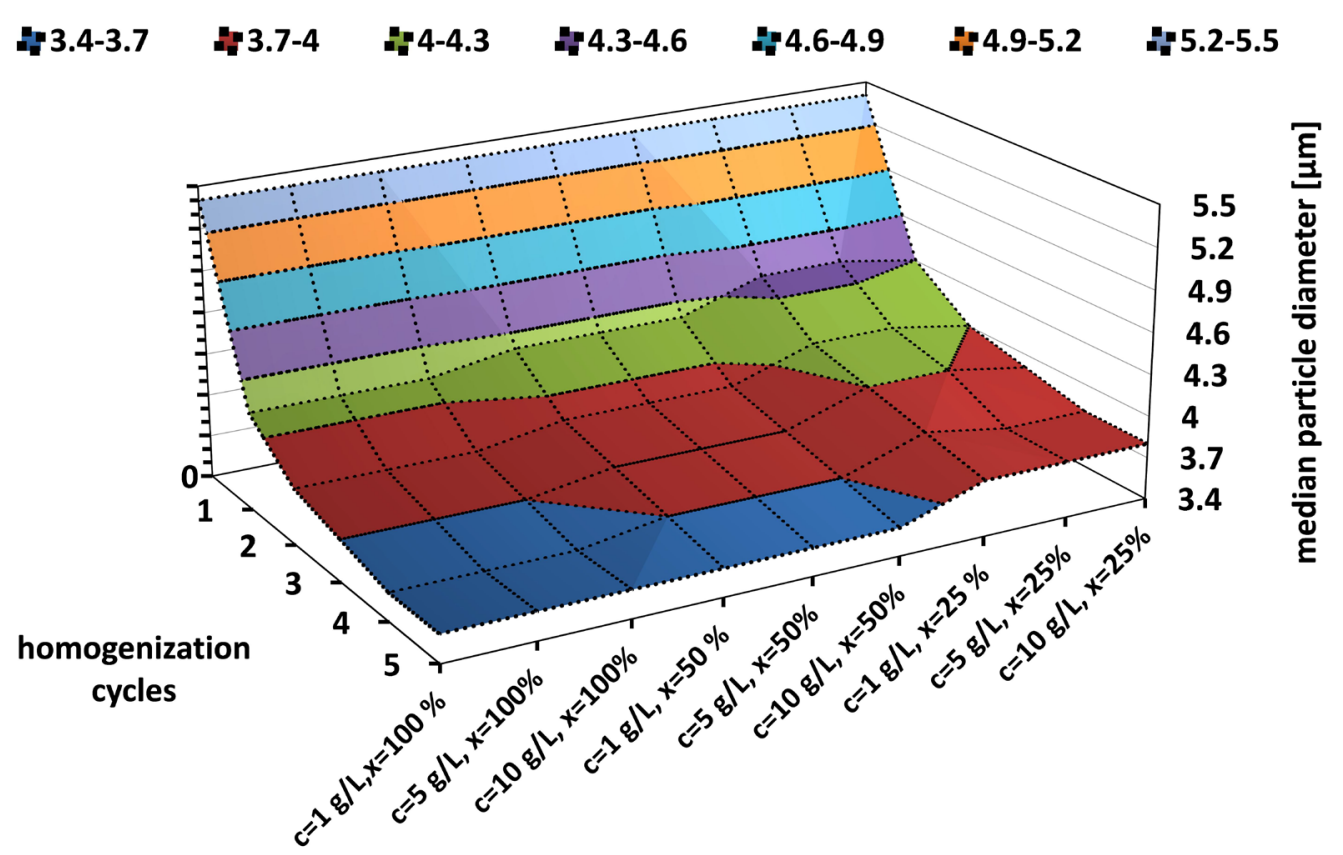

particle concentration $[\mathrm{g} / \mathrm{L}]$ and power adjustment [\%]

Figure 3. Measured particle diameter $\mathrm{d}_{50}$ of three magnetic particle suspensions S1-S3 at 50, 100 and $200 \mathrm{~W}$ ultrasonic power.

\subsection{Particle Retention Studies}

The filter matrix can be built with various geometries as for example rods or plates with notches. Although cylindrical matrix filaments were more adequate for high-gradient magnetic separation in terms of fluid flow around the filaments, steel plates with notches and cuboid filaments were used here for the systemic study of filter matrices. With such filter matrices a higher magnetic force gradient could be generated at the edges of the notches. Moreover, the assembling of the magnetic filter, which will play a role for future use, is easier in this case. The manufacturing of filter plates requires techniques to produce the required notches without degrading the stainless steel at the cutting edges. Therefore filter plates were made by laser cutting, stamping and micro waterjet cutting (see Figure 4).

Figure 4 M1 shows the edges of a stamped and M2 of a laser cut filter plate. By laser cutting a degradation of the stainless steel occurs due to thermal decomposition which leads to staining. The edges of plates which were micro waterjet cut are shown in Figure 4 M3 and M4. Hereby M3 shows the surface of the side of the ingoing waterjet and M4 the opposite surface. Electro polished edges of a filter plate, which was micro waterjet cut before, are shown in Figure 4 M5 and M6. The average roughness value of the electro polished steel plate surface was $\mathrm{R}_{\mathrm{A}}=0.095 \pm 0.016 \mu \mathrm{m}$. It can clearly be seen that micro waterjet cutting followed by electro polishing should be used to produce steel plates for magnetic filters. This technique offers two advantages: The cutouts are very accurate and different geometries can be generated flexible and easily.

The particle retention was tested with five different matrices A-E. The filter matrices A-D were formed with stacked filter plates which were equipped with widthwise notches. Matrices A and B were built with 8 stacked filter plates with a varying amount of filaments. Matrices C and D were built with 11 and 14 stacked filter plates respectively. The dimensions of the plates were $26 \mathrm{~mm}$ by $80 \mathrm{~mm}$ (matrices $\mathrm{A}$ and B) or $26 \mathrm{~mm}$ by $128 \mathrm{~mm}$ (matrices $\mathrm{C}$ and $\mathrm{D}$ ). The widthwise cutouts had the dimension $1.5 \mathrm{~mm}$ by $22 \mathrm{~mm}$ (separated by crossbars of $1.636 \mathrm{~mm}$ ) in case of matrices A and B and $1 \mathrm{~mm}$ by $20 \mathrm{~mm}$ (separated by crossbars of $1 \mathrm{~mm}$ ) in case of matrices C and D. The filter plates had a thickness of $0.75 \mathrm{~mm}$ in case of matrices A and B and of $0.5 \mathrm{~mm}$ in case of matrices $C$ and D. Furthermore $7.5 \mathrm{~g}$ stainless steel wool (coarse grade with $0.2 \mathrm{~mm}$ by $0.2 \mathrm{~mm}$ filaments) with a length of $128 \mathrm{~mm}$ was also used as a filter matrix E, whereby the filaments were aligned lengthwise in fluid flow direction. The volume of the steel wool tuft filled the whole volume of the filter chamber so that only 


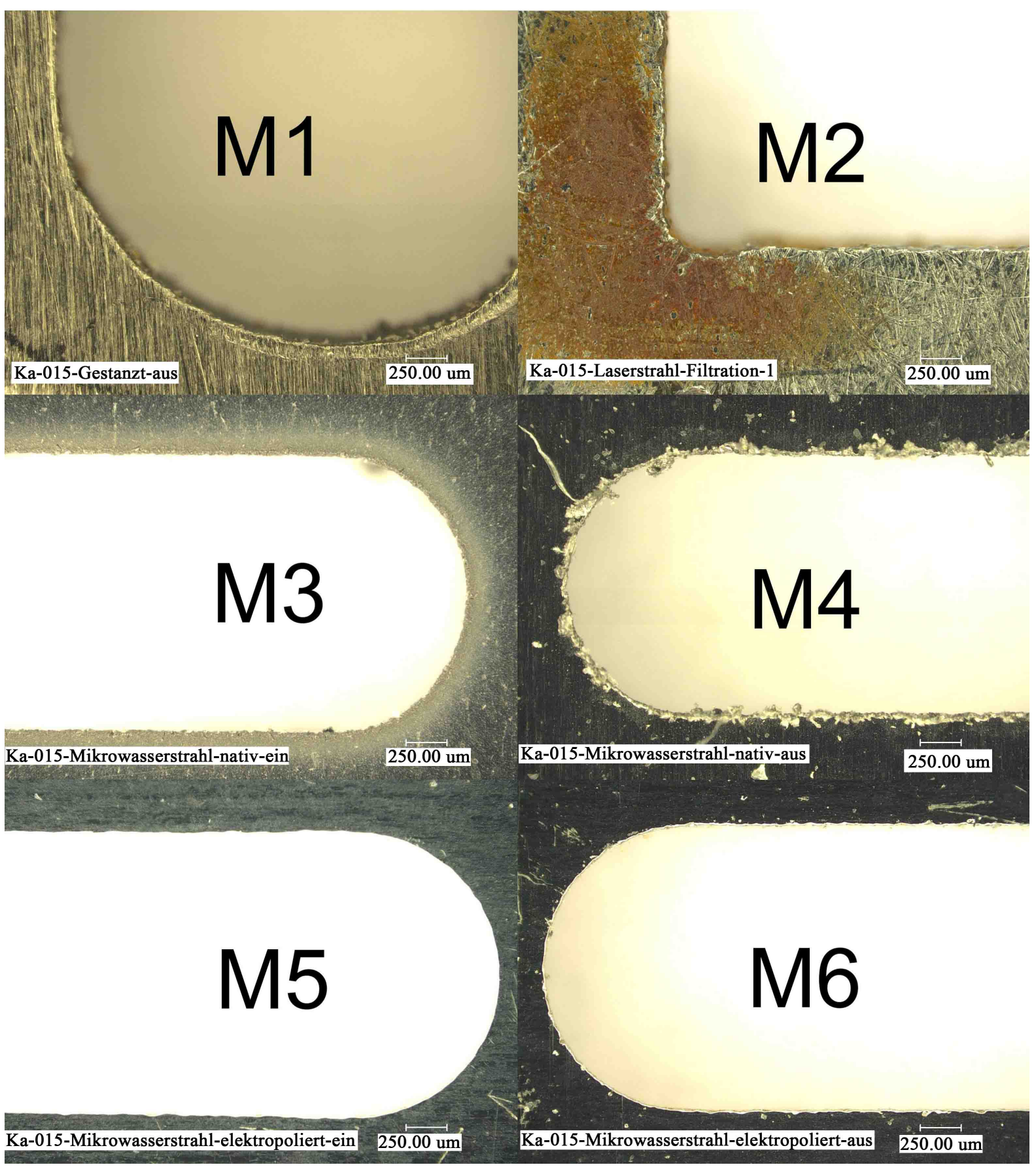

Figure 4. Images of filter plates which are stamped (M1), laser cut (M2), micro waterjet cut (M3 - M4) and electro polished after micro waterjet cut (M5 - M6).

minor holes were present. The magnetic pole surfaces of the magnetic yoke had identical dimensions as matrices A and B. So the filter matrices type C, D and E overlap the pole surfaces equidistant in the lengthwise direction.

The particle retention tests were carried out with two particle suspensions ( 0.5 and $3 \mathrm{~g} \cdot \mathrm{L}^{-1} \mathrm{M}$-PVA C22). The volume flow was adjusted between 100 and $200 \mathrm{~mL} \cdot \mathrm{min}^{-1}$. The total particle mass pumped into the magnetic filter was $3 \mathrm{~g}$ each. The particle concentration in the filtrate was measured at-line in flow-through mode. The concentration data was further processed to calculate the cumulative particle mass in the filtrate. In Table 2 the used filter matrices and the result data are summarized. Overall the steel wool matrix (matrix E) has the best 
Table 2. Overview of the used filter matrices and result data (triplet repetition).

\begin{tabular}{|c|c|c|c|c|c|c|c|}
\hline Matrix & $\begin{array}{l}\text { Number of } \\
\text { plates [-] }\end{array}$ & $\begin{array}{c}\text { Suspension } \\
\text { concentration }[\mathrm{g} / \mathrm{L}]\end{array}$ & $\begin{array}{l}\text { Volume flow } \\
\text { [mL/min] }\end{array}$ & $\begin{array}{c}\text { Free filter } \\
\text { volume }[\mathrm{mL}]\end{array}$ & $\begin{array}{l}\text { Total } \\
\text { edge length } \\
{[\mathrm{mm}]}\end{array}$ & $\begin{array}{c}\text { Measured } \\
\text { particle loss [\%] }\end{array}$ & $\begin{array}{c}\text { Standard } \\
\text { deviation [\%] }\end{array}$ \\
\hline \multirow{4}{*}{ A } & & \multirow{2}{*}{0.5} & 100 & \multirow{4}{*}{51.78} & \multirow{4}{*}{24,008} & 0.35 & 0.01 \\
\hline & & & 200 & & & 1.05 & 0.04 \\
\hline & & \multirow{2}{*}{3} & 100 & & & 0.08 & 0.00 \\
\hline & 8 & & 200 & & & 0.33 & 0.07 \\
\hline \multirow{3}{*}{ B } & & 0.5 & 100 & & & 0.52 & 0.27 \\
\hline & & \multirow{2}{*}{3} & 100 & 54.22 & 17,560 & 0.09 & 0.00 \\
\hline & & & 200 & & & 0.22 & 0.01 \\
\hline \multirow{4}{*}{ C } & \multirow{4}{*}{11} & \multirow{3}{*}{0.5} & 100 & \multirow{4}{*}{48.68} & \multirow{4}{*}{70,554} & 0.28 & 0.06 \\
\hline & & & 200 & & & 0.75 & 0.09 \\
\hline & & & 100 & & & 0.08 & 0.00 \\
\hline & & 3 & 200 & & & 0.11 & 0.00 \\
\hline \multirow{4}{*}{ D } & \multirow{4}{*}{14} & \multirow{2}{*}{0.5} & 100 & \multirow{4}{*}{45.62} & \multirow{4}{*}{89,796} & 0.25 & 0.02 \\
\hline & & & 200 & & & 1.26 & 0.06 \\
\hline & & \multirow{2}{*}{3} & 100 & & & 0.07 & 0.00 \\
\hline & & & 200 & & & 0.13 & 0.00 \\
\hline \multirow{2}{*}{$\mathrm{E}$} & \multirow{2}{*}{$\begin{array}{c}7.5 \mathrm{~g} \mathrm{~g} \\
\text { steel wool }\end{array}$} & 0.5 & 200 & \multirow{2}{*}{58.93} & \multirow{2}{*}{97,280} & 0.20 & 0.02 \\
\hline & & 3 & 200 & & & 0.03 & 0.01 \\
\hline
\end{tabular}

particle retention capacity, whereby the calculated total edge length and free filter volume are the highest. The next best matrices are in descending order C, A, D, B. To obtain a maximum retention the following parameters should be chosen (see Table 2):

1) High total edge length and herewith high number of filaments

2) High suspension concentration

3) Low volume flow and high free filter volume (resulting in low linear velocity)

In Figure 5 the particle concentration in the filtrate is plotted against the cumulative particle inlet mass for the matrices A, C, D and E. In general it could be observed that the highest particle concentrations in the filtrate were obtained when low concentrated particle suspensions were pumped with a high volume flow through the magnetic filter (see Table 2). Therefore filtration results of suspensions with a concentration of $0.5 \mathrm{~g} \cdot \mathrm{L}^{-1}$ magnetizable particles and varying volume flows are selected for demonstration in Figure 5. The comparison of the curves shows that the course differs for each matrix. Furthermore the total particle mass in the filtrate, which represents the total loss of magnetizable particles, differs as a logical consequence, too (see Table 2). In case of matrices $\mathrm{A}$ and $\mathrm{E}$ the particle concentration in the filtrate is slow, but steadily ascending with an increasing cumulative particle inlet mass (see Figure 5). In case of matrices $C$ and $D$ the particle concentrations in the filtrate were high at the start of the filtration, decrease to a minimum and increase then steadily again.

It was found that the cumulative particle mass in the filtrate can be estimated with an empiric equation with a few restrictions (see Equation (3) with $p_{1}$ and $p_{2}=$ empiric parameters, $m_{I N}(t)=$ cumulative inlet particle mass, $m_{\text {OUT }}(t)=$ cumulative particle mass in the filtrate).

$$
m_{\text {OUT }}(t)=p_{1} \cdot m_{I N}(t)+e^{p_{2} \cdot m_{I N}(t)}-1
$$

In Figure 6 the experimental and calculated results are shown for comparison. It can be seen, that the calculated results are in good correspondence to the experimental data especially in case of matrix A with a volume flow of $100 \mathrm{~mL} \cdot \mathrm{min}^{-1}$. The discrepancy is a little bit higher when the volume flow was adjusted to $200 \mathrm{~mL} \cdot \mathrm{min}^{-1}$. The matrix E was tested with 200 and $400 \mathrm{~mL} \cdot \mathrm{min}^{-1}$ and the discrepancy is overall low. The approximation by use of Equation (3) is not as good in case of matrices $\mathrm{C}$ and $\mathrm{D}$ with a volume flow of $100 \mathrm{~mL} \cdot \mathrm{min}^{-1}$ and is even 
unsuitable when the volume flow is adjusted to $200 \mathrm{~mL} \cdot \mathrm{min}^{-1}$. The results of matrix B were not included into this analysis, because here the executed filtrations of a suspension with $0.5 \mathrm{~g} \cdot \mathrm{L}^{-1}$ magnetic particles showed significantly higher deviations so that the parameter estimation would not be precise in this case.

In Table 3 the empiric parameters are listed for the curves shown in Figure 6.

Based on Equation (3) and the estimated parameters $p_{1}$ and $p_{2}$ the amount of magnetic particles within the filtrate and here with the loss of immobilized biocatalyst for the matrices A and E can be calculated. In case of expensive biocatalysts the calculation provides information on the profitability of the high gradient magnetic separation. In this context the subsequent cleaning of the filter represents an important factor. The optimized cleaning is described in chapter 3.3.

The comparison of the curves in Figure 6 provides furthermore information on the impact of a magnetic particle clogging. It can be assumed that a clogging in the front part of the magnetic filter represents the main reason for the different courses. The filter matrix A has the same size as the magnetic pole surfaces and so the gradient of the magnetic flux is very high at the first filaments of the magnetic filter. Herewith the clogging builds up quicker than in case of matrix $C$ and $D$. Due to the extended length of matrices $C$ and $D$, the magnetic force acting
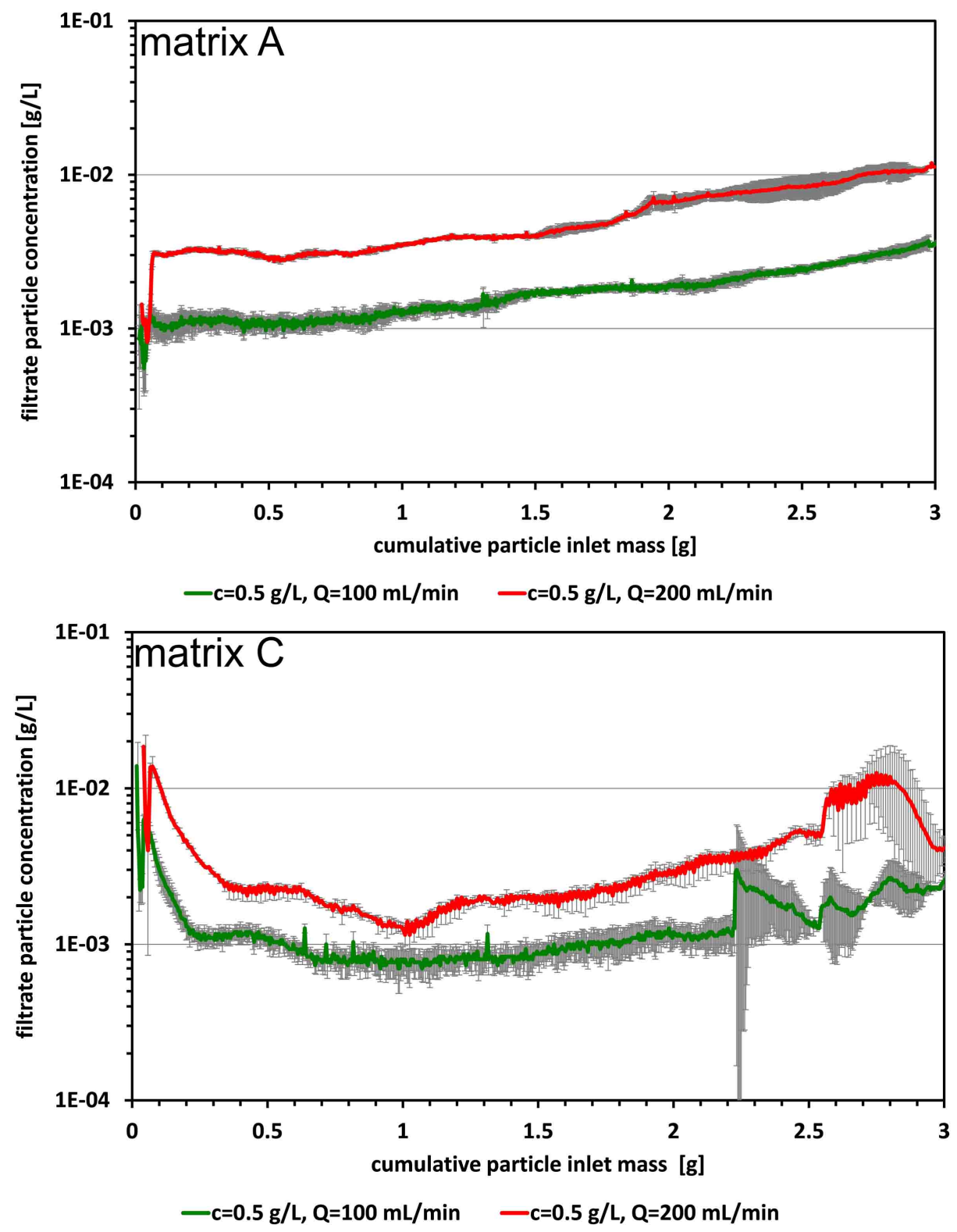

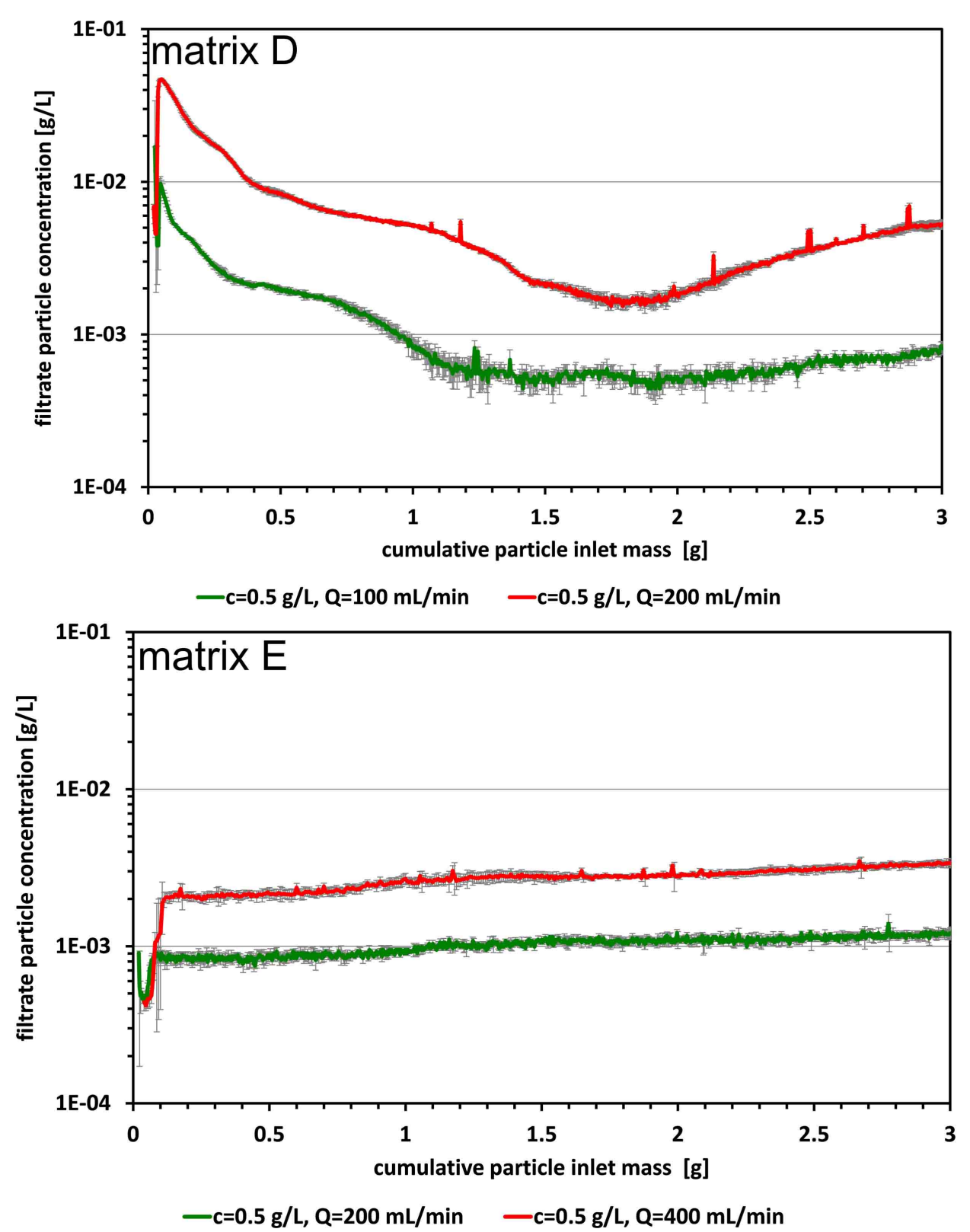

Figure 5. Measured particle concentration in the filtrate as function of the cumulative particle inlet mass during magnetic filtrations with matrices A, C, D and E.

Table 3. Empiric parameters of Equation (3) for the matrices A, C, D and E.

\begin{tabular}{cccc}
\hline matrix & $\mathrm{Q}[\mathrm{mL} / \mathrm{min}]$ & $p_{1}[-]$ & $p_{2}[-]$ \\
\hline $\mathrm{A}$ & 100 & 0.0393 & -0.0380 \\
& 200 & 0.0760 & -0.0732 \\
$\mathrm{C}$ & 100 & 0.0044 & -0.0016 \\
& 200 & 0.0402 & -0.0356 \\
$\mathrm{D}$ & 100 & 0.0046 & -0.0014 \\
& 200 & 0.0151 & +0.0001 \\
$\mathrm{E}$ & 200 & 0.0043 & -0.0023 \\
& 400 & 0.0080 & -0.0030 \\
\hline
\end{tabular}


on the incoming magnetizable particles increases from the start of the matrix up to the point where the pole surfaces start. This means the clogging in the front part of the filter matrix occurs in a prolonged volume in comparison to matrix A. Incoming magnetizable particles are less likely to attach onto the clogging, because the density of the clogging is comparatively smaller. Additionally, due to the higher linear velocity of the fluid in matrix C and D more particles were lost at the start of the magnetic filtration so that the clogging builds up slower. The particle loss declines after that with the rising clogging. When the retention capacity of the magnetic filter decreases in the further course of the magnetic filtration the particle loss increases again.

But in contrary to this principle, matrix E, which is as long as matrix $\mathrm{C}$ and $\mathrm{D}$, has the lowest loss of particles during filtration. Here the difference in the matrix geometry is the main reason for the good particle retention in a steel wool matrix. The significantly larger number of filament corners and the low linear flow velocity improves
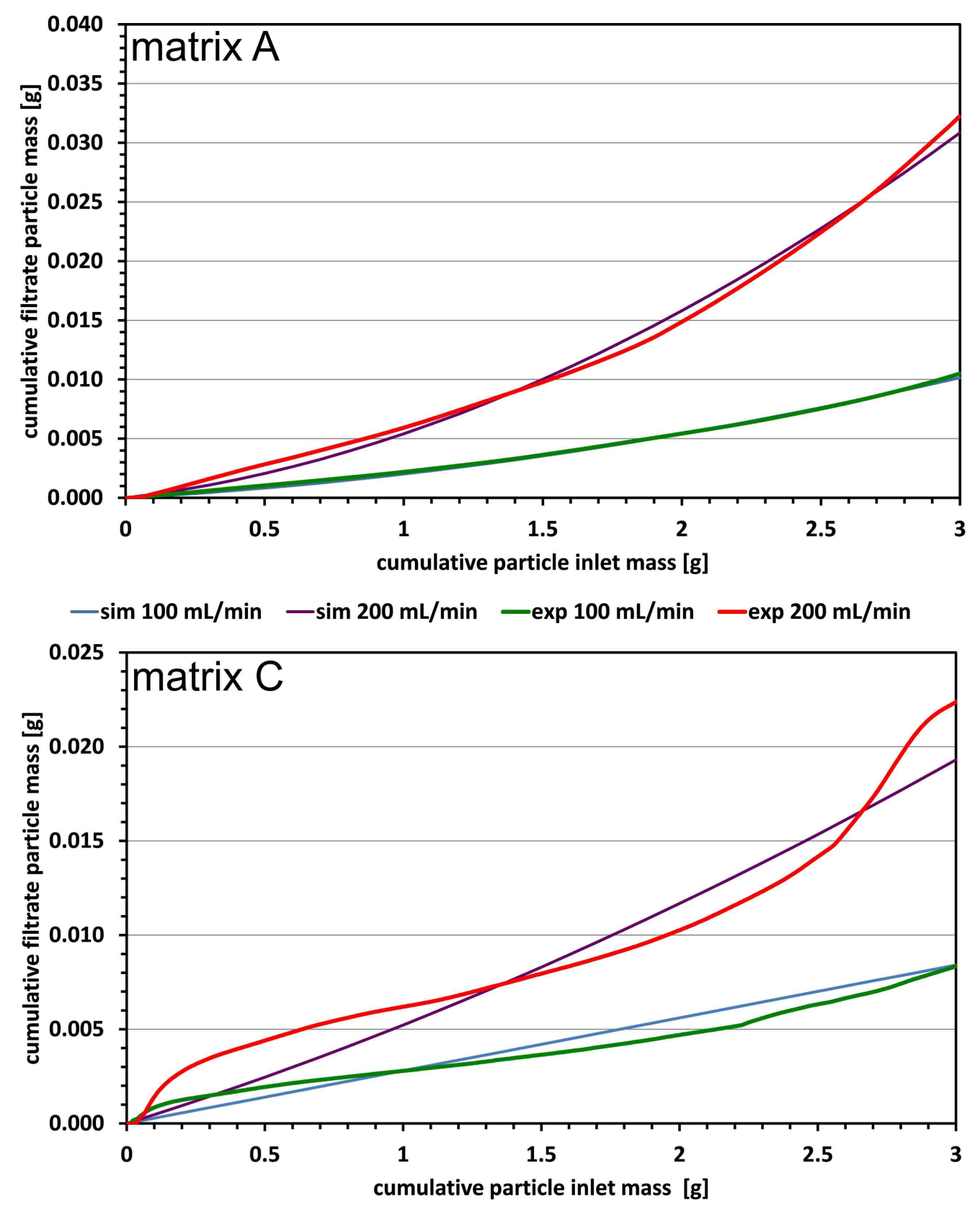

- $\operatorname{sim} 100 \mathrm{~mL} / \mathrm{min}-\operatorname{sim} 200 \mathrm{~mL} / \mathrm{min}-\exp 100 \mathrm{~mL} / \mathrm{min}-\exp 200 \mathrm{~mL} / \mathrm{min}$ 

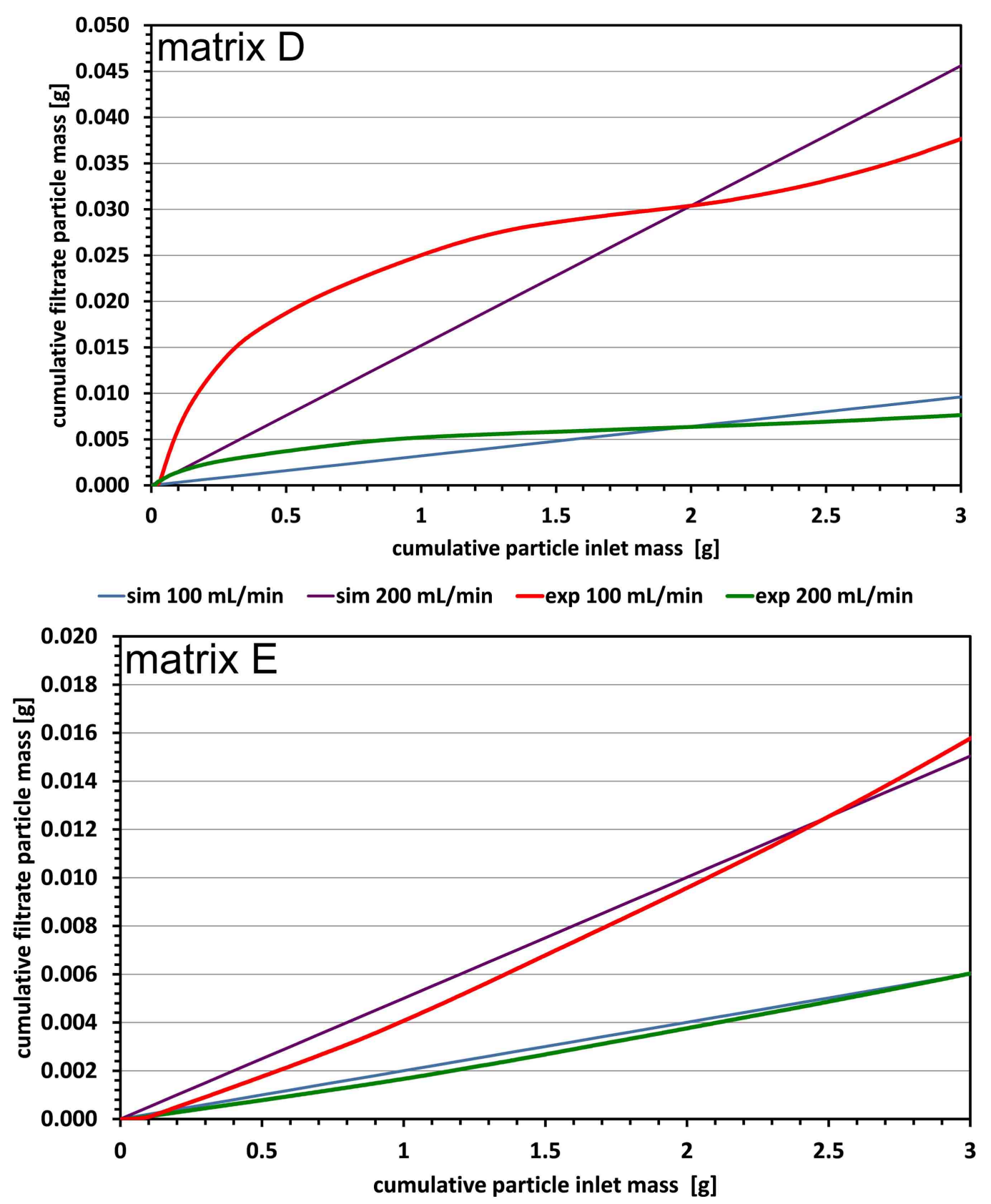

- $\operatorname{sim} 200 \mathrm{~mL} / \mathrm{min}-\operatorname{sim} 400 \mathrm{~mL} / \mathrm{min}-\exp 200 \mathrm{~mL} / \mathrm{min}-\exp 400 \mathrm{~mL} / \mathrm{min}$

Figure 6. Measured and calculated cumulative particle mass in the filtrate as a function of the cumulative particle inlet mass during magnetic filtrations with matrices A, C, D and E.

the clogging.

Images of the matrices $\mathrm{A}, \mathrm{C}, \mathrm{D}$ and $\mathrm{E}$ with a loading of $5 \mathrm{~g}$ magnetizable particles are shown in Figure 7. Before taking the pictures suspensions with $3 \mathrm{~g} \cdot \mathrm{L}^{-1}$ magnetizable particles were pumped with a volume flow of $100 \mathrm{~mL} \cdot \mathrm{min}^{-1}$ through the filter. It can be seen that the particle deposits decrease from the inlet (bottom) to the outlet (top). In general the optical observations underline the assumption that the clogging improves the particle retention during filtration and the particle deposits are rather concentrated at the inlet of the magnetic filter.

The geometry of the clogging showed a certain similarity despite of variations from experiment to experiment. At the outer areas of the filter matrices the particle deposits reach far in flow direction. The center areas of the 
matrix have less magnetic particle deposits. In case of matrix A the particle deposits reach heights of up to 50 $\mathrm{mm}$ from the inlet of the filter matrix, whereby the particle deposits were especially thin around the matrix fixture. In the center area of the matrices the clogging is rather concentrated at a height below $20 \mathrm{~mm}$. In order to minimize the movement of the particle deposits at the outer edges in flow direction, matrix $\mathrm{C}$ and $\mathrm{D}$ were modified at the edges (see Figure 8). Protruding filaments produce more turbulence at the edges and minimize the flow velocity in this area in comparison to matrix A and B. Overall it was observed that the clogging varied with the volume flow and the particle concentration of the suspension. When the linear fluid velocity became greater the length of the clogging also increased resulting in less dense clogging.

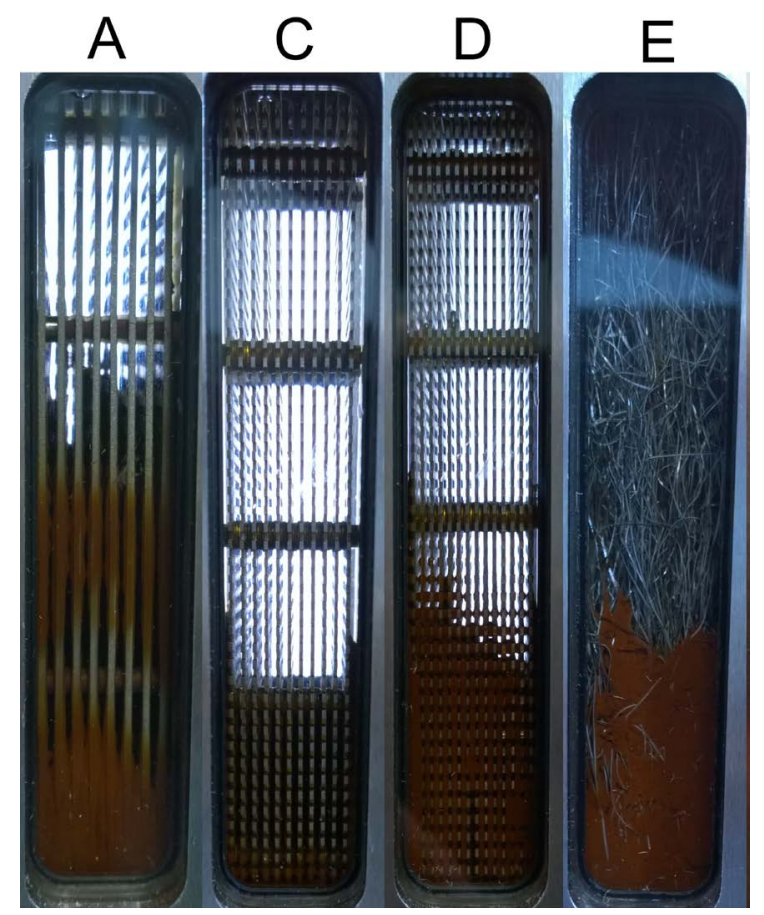

Figure 7. Images of clogging in the matrices A, C, D and $\mathrm{E}$ (after loading with $5 \mathrm{~g}$ magnetizable particles).

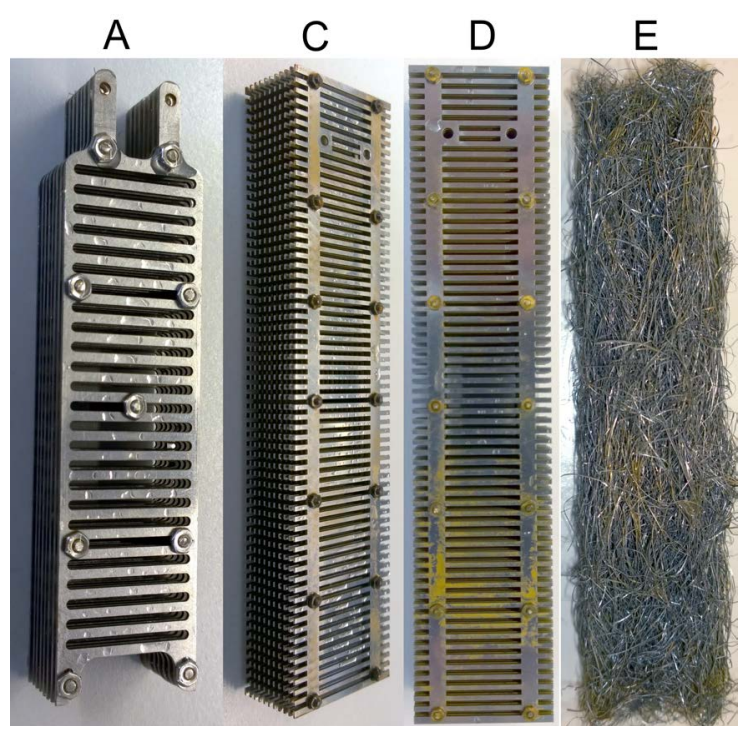

Figure 8. Matrices A, C, D and E after cleaning (load of 6 g magnetizable particles before cleaning). 


\subsection{Optimization of the Rinsing Procedure}

After investigations on the particle retention the rinsing procedure was optimized. The rinsing of the agglomerated particles in the filter chamber requires high shear rates at the boundaries of the filter chamber and the filter matrix. The shear rates could be applied by a single- or a two-phase flow. In previous studies several methods were tested [15]. In this study pressured air (0.2 MPa) was injected in the tubing after the peristaltic pump through a t-connector. Hereby it was possible to produce a flow of water with dispersed air bubbles by pumping water and injecting pressured air simultaneously. More than 0.2 MPa could not be applied because of the pressure stability of the pump tubing. Furthermore the adjusted volume flow of the pump had to be greater than 200 $\mathrm{mL} \cdot \mathrm{min}^{-1}$ preferably. One of the main advantages of this rinsing method is the production of highly dispersed air bubbles.

The large area of the water-air interface produces high shear rates on the filter matrix during the cleaning procedure. The shear rates produced with this method could be further raised by injecting the pressured air in pulses. The injection was performed for $1 \mathrm{~s}$ followed by a further second switched off. Because accurate sampling and measurement of the minor particle residues on the filter matrices are nearly impossible, an optical checking was performed. In Figure 8 the images of the cleaned matrices A, C, D and E are shown after application of the above described rinsing method. Before rinsing all matrices were loaded with $6 \mathrm{~g}$ M-PVA C22 particles. Matrix A had no visual particle residues on the surfaces whereas matrices $\mathrm{C}$ and $\mathrm{D}$ had some minor but clearly visible particle residues on the lengthwise matrix filaments. Matrix $\mathrm{E}$ had some minor discolorations of the filaments due to particle deposits. These discolorations were found only at the outer shell of the matrix. Overall, a de facto complete removal of magnetizable particles is possible with the optimized rinsing procedure in every case.

\section{Summary and Conclusion}

In the presented study, it was found that the clogging inside the filter matrix is essential for the particle retention in a magnetic filter. The particles build dense deposits in the area of the edges of the magnetic pole surfaces at the inlet of the filter chamber. This effect can be explained by high gradients of the magnetic flux density in this area. The clogging supports the particle retention because magnetizable particles, which enter the filter chamber, are stopped by the dense particle agglomerates. By inserting a filter matrix, which is longer than the length of the pole surfaces, the clogging of the magnetic filter appears delayed. Herewith the separation becomes worse. To use a prolonged filter matrix in order to homogenize the fluid flow in a magnetic filter is consequently unsuitable. The use of a flow homogenisator made of a non-magnetizable material is recommended instead.

The cleaning procedure could be optimized with a high volume flow of rinsing liquid and a simultaneous pulsed injection of pressured air. The minor residues of magnetizable particles in the filter chamber, which cannot be removed, must be taken into consideration when implementing high-gradient magnetic separation in a biocatalytic process. Minor concentrations of magnetizable particles in the filtrate could also be an important deterioration factor in a process. To overcome the second factor, the use of a dead end ultra- or microfiltration after the magnetic filtration could prevent contamination of the product stream with immobilized enzymes on magnetizable carriers.

\section{Acknowledgements}

The authors acknowledge financial support received from the German Federal Ministry of Education and Research (BMBF) (Project reference no: 0316057B).

\section{References}

[1] Datta, S., Christena, L.R. and Rajaram, Y.R.S. (2013) Enzyme Immobilization: An Overview on Techniques and Support Materials. 3 Biotech, 3, 1-9. http://dx.doi.org/10.1007/s13205-012-0071-7

[2] Homaei, A.A., Sariri, R., Vianello, F. and Stevanato, R. (2013) Enzyme Immobilization: An Update. Journal of Chemical Biology, 6, 185-205. http://dx.doi.org/10.1007/s12154-013-0102-9

[3] Hubbuch, J.J., Matthiesen, D.B., Hobley, T.J. and Thomas, O.R. (2001) High Gradient Magnetic Separation versus Expanded Bed Adsorption: A First Principle Comparison. Bioseparation, 10, 99-112. http://dx.doi.org/10.1023/A:1012034923621 
[4] Hubbuch, J.J. and Thomas, O.R. (2002) High-Gradient Magnetic Affinity Separation of Trypsin from Porcine Pancreatin. Biotechnology and Bioengineering, 79, 301-313. http://dx.doi.org/10.1002/bit.10285

[5] Heebøll-Nielsen, A., Choe, W.S., Middelberg, A.P. and Thomas, O.R. (2003) Efficient Inclusion Body Processing Using Chemical Extraction and High Gradient Magnetic Fishing. Biotechnology Progress, 19, 887-898. http://dx.doi.org/10.1021/bp025553n

[6] Heebøll-Nielsen, A., Dalkiær, M., Hubbuch, J.J. and Thomas, O.R. (2004) Superparamagnetic Adsorbents for HighGradient Magnetic Fishing of Lectins out of Legume Extracts. Biotechnology and Bioengineering, 87, 311-323. http://dx.doi.org/10.1002/bit.20116

[7] Meyer, A., Hansen, D.B., Gomes, C.S., Hobley, T.J., Thomas, O.R. and Franzreb, M. (2005) Demonstration of a Strategy for Product Purification by High-Gradient Magnetic Fishing: Recovery of Superoxide Dismutase from Unconditioned Whey. Biotechnology Progress, 21, 244-254. http://dx.doi.org/10.1021/bp049656c

[8] Franzreb, M. (2003) Magnettechnologie in der Verfahrenstechnik wässriger Medien. Wissenschaftliche Berichte FZKA, 6916, A-212.

[9] Menzel, K., Lindner, J. and Nirschl, H. (2011) Treatment of Highly Viscous Lubricants by High Gradient Magnetic Separation Technique. FILTECH Conference Proceedings, Wiesbaden, March 22-24, 103-108.

[10] Mizuno, N., Mishima, F., Akiyama, Y., Okada, H., Hirota, N., Matsuura, H. and Nishijima, S. (2015) Removal of Iron Oxide with Superconducting Magnet High Gradient Magnetic Separation from Feed-Water in Thermal Plant. IEEE Transactions on Applied Superconductivity, 25, 1-4. http://dx.doi.org/10.1109/TASC.2015.2392624

[11] Schultz, N., Syldatk, C., Franzreb, M. and Hobley, T.J. (2007) Integrated Processing and Multiple Re-Use of Immobilised Lipase by Magnetic Separation Technology. Journal of Biotechnology, 132, 202-208. http://dx.doi.org/10.1016/j.jbiotec.2007.05.029

[12] Maury, T.L., Ottow, K.E., Brask, J., Villadsen, J. and Hobley, T.J. (2012) Use of High-Gradient Magnetic Fishing for Reducing Proteolysis during Fermentation. Biotechnology Journal, 7, 909-918. http://dx.doi.org/10.1002/biot.201100376

[13] Ebner, N., Gomes, C.S., Hobley, T.J., Thomas, O.R. and Franzreb, M. (2007) Filter Capacity Predictions for the Capture of Magnetic Microparticles by High-Gradient Magnetic Separation. IEEE Transactions on Magnetics, 43, 19411949. http://dx.doi.org/10.1109/TMAG.2007.892080

[14] Hoffmann, C., Franzreb, M. and Höll, W.H. (2002) A Novel High-Gradient Magnetic Separator (HGMS) Design for Biotech Applications. IEEE Transactions on Applied Superconductivity, 12, 963-966. http://dx.doi.org/10.1109/TASC.2002.1018560

[15] Kampeis, P., Bewer, M. and Rogin, S. (2009) Einsatz von Magnetfiltern in der Bioverfahrenstechnik-Teil 1: Vergleich verschiedener Verfahren zum Rückspülen der Magnetfilter. Chemie Ingenieur Technik, 81, 275-281. http://dx.doi.org/10.1002/cite.200800121

[16] König, S., Schumann, C. and Kampeis, P. (2010) Einsatz von Magnetfiltern in der Bioverfahrenstechnik—Teil 2: Trennung von Biomasse und Magnetbeads im Magnetfilter. Chemie Ingenieur Technik, 82, 641-650. http://dx.doi.org/10.1002/cite.200900106

[17] Kampeis, P., Lieblang, M. and Krause, H.J. (2011) Einsatz von Magnetfiltern in der Bioverfahrenstechnik-Teil 3: Neues Messverfahren zur Quantifizierung von Magnetbeads in strömenden Suspensionen. Chemie Ingenieur Technik, 83, 851-857. http://dx.doi.org/10.1002/cite.201000191

[18] Schumann, C., Rogin, S., Schneider, H., Tippkötter, N., Oster, J. and Kampeis, P. (2015) Simultaneous Atline Quantification of Magnetic Particles and Microorganisms in the HGMS Filtration. Chemie Ingenieur Technik, 87, 137-149. http://dx.doi.org/10.1002/cite.201300158

[19] Pasteur, A., Tippkotter, N., Kampeis, P. and Ulber, R. (2014) Optimization of High Gradient Magnetic Separation Filter Units for the Purification of Fermentation Products. IEEE Transactions on Magnetics, 50, 1-7. http://dx.doi.org/10.1109/TMAG.2014.2325535

[20] Chang, C.F., Chang, C.Y. and Hsu, T.L. (2011) Removal of Fluoride from Aqueous Solution with the Superparamagnetic Zirconia Material. Desalination, 279, 375-382. http://dx.doi.org/10.1016/j.desal.2011.06.039

[21] Käppler, T. (2008) Prozessintensivierung durch feldunterstützte Bioseparation: Elektrofiltration und in situ Magnetseparation. Univ.-Verlag Karlsruhe.

[22] Hoffmann, C. (2003) Einsatz magnetischer Separationsverfahren zur biotechnologischen Produktaufbereitung. Doctoral Dissertation, Forschungszentrum Karlsruhe in der Helmholtz-Gemeinschaft FZKA.

[23] Shaikh, Y.S., Seibert, C., Schumann, C., Ferner, M.J., Raddatz, H. and Kampeis, P. (2016) Study on Optimizing a Rotor-Stator Filter Matrix for High-Gradient Magnetic Separation of Functionalized Magnetic Particles. Engineering in Life Sciences, 1618-2863. http://dx.doi.org/10.1002/elsc.201500115 
[24] Shaikh, Y.S., Schussmann, S., Lieblang, M. and Kampeis, P. (2015) Einsatz eines Ultraschall-Durchflussmessgerätes zur Regelung des Volumenstroms in der Hochgradienten-Magnetseparation. Chemie Ingenieur Technik, 87, 618-625. http://dx.doi.org/10.1002/cite.201400048

[25] Holschuh, K. and Schwämmle, A. (2005) Preparative Purification of Antibodies with Protein A-An Alternative to Conventional Chromatography. Journal of Magnetism and Magnetic Materials, 293, 345-348. http://dx.doi.org/10.1016/j.jmmm.2005.02.050 